\title{
Analysis of the Sedimentation Characteristics of Ultrafine Tailings Based on an Orthogonal Experiment
}

\author{
Chang-hong Li, Yue-qi Shi $\mathbb{D}^{D}$, Peng Liu, and Ning Guo \\ School of Civil and Resource Engineering, University of Science and Technology Beijing (USTB), Beijing 100083, China \\ Correspondence should be addressed to Yue-qi Shi; syq_shi@126.com
}

Received 14 October 2019; Accepted 14 November 2019; Published 28 November 2019

Academic Editor: Akbar Heidarzadeh

Copyright (C) 2019 Chang-hong Li et al. This is an open access article distributed under the Creative Commons Attribution License, which permits unrestricted use, distribution, and reproduction in any medium, provided the original work is properly cited.

\begin{abstract}
Due to continuous improvements in the beneficiation process, the size of tailings has decreased. In many mines, more than $50 \%$ of the total tailings are finer than $74 \mu \mathrm{m}$. Ultrafine tailings exhibit a slow settling velocity and uneven settling, which pose new challenges to the safety and stability of tailings dams. In this paper, ultrafine iron tailings from the Makeng Iron Mine in Longyan City, Fujian Province, were used as the research object. A four-factor, three-level orthogonal test method was used to study the sedimentation characteristics of ultrafine tailings with four common curing agent materials, including polyacrylamide, polyaluminum chloride, polyaluminum sulfate, and polyferric sulfate. The results show that when the pulp concentration is $30 \%$, the polyacrylamide is cationic and the molecular weight is 10 million, the optimal content of the flocculant is 3\%o, the optimum dose of the polyaluminum chloride with a content of 28 is $0.1 \%$, the optimum dose of polyaluminum sulfate is $1 \%$, and the optimum dose of polymeric ferric sulfate is $1 \%$. When the flocculant is mixed according to the proportion of $2 \%$ polyacrylamide, $0.05 \%$ polyaluminum chloride, $1 \%$ polyaluminum sulfate, and $1.0 \%$ polyferric sulfate, the sedimentation speed of the ultrafine tailings is fast, and the supernatant liquid is clear. The results of multivariate nonlinear regression analysis of the sedimentation curve show that the primary and secondary factors affecting sedimentation are polyacrylamide $>$ polyaluminum sulfate $>$ polyaluminum chloride $>$ polyferric sulfate. When the optimal ratio is applied, the cohesion (c) of ultrafine tailings increases from $27 \mathrm{kPa}$ to $68.75 \mathrm{kPa}$ and the internal friction angle $(\varphi)$ increases from $25.53^{\circ}$ to $27.53^{\circ}$, which shows that the shear strength improves and the stability of the tailings dam increases. The economic analysis of the composite flocculant with the optimal ratio shows that the flocculant with the optimal proportion has an obvious economic advantage over polyacrylamide alone.
\end{abstract}

\section{Introduction}

China is a major producer of mined materials and possesses some of the richest mineral resources, reserves, and production in the world [1]. With the continuous development and utilization of mineral resources, the grade of mined ores is declining annually. The minerals are in a complex state; the high-grade, easy-to-separate rich mineral resources are becoming gradually depleted; and the mineral concentration of deposits has gradually decreased. All of these factors lead to the need for more ore. Thus, the separation and enrichment of useful minerals by grinding to fine (average particle size less than 30 microns) or even ultrafine (average particle size less than 10 microns) particle size levels [2] has promise.
Ultrafine tailings have a small particle size, giving them a large specific surface area and high reactivity [3]. Therefore, compared with general tailings, a large number of ultrafine tailings are difficult to settle quickly in a limited time [4-6], and suspended ultrafine tailings particles can easily cause blockage in drainage systems. At the same time, tailings sand is used in mining engineering projects, and its strength is not high. Tailings sand is concentrated at weak points, such as the dam foundation and the dam shoulder. The formation of voids inside dam bodies may lead to their partial collapse, which may cause tailings dams to break. Therefore, finding suitable flocculants, accelerating the sedimentation of tailings slurries, and promoting the aggregation of ultrafine tailings particles are of great importance for improving the safety and stability of tailings dams. 
In recent years, domestic and foreign research on flocculation and sedimentation has been carried out at both the macroscale and the microscale; however, the flocculation sedimentation process is a complex physical and chemical process [7].

Eswaraiah et al. [8] and Jiao et al. [9] studied the sedimentation characteristics of ultrafine iron tailings. They added cationic, anionic, and nonionic flocculants to the slurry in different $\mathrm{pH}$ ranges. It was found that the anionic flocculant had the best effect, and a small addition resulted in rapid sedimentation, while cationic and nonionic types were not beneficial even if a large amount was added. Selomulya et al. [10] used optical laser microscopy and X-ray diffraction to study the microstructure of floc particles and sedimentary layers. Jiao et al. [11] studied the static settlement patterns and mechanism of a range of tailings sizes and used a static flocculation sedimentation experiment of tailings in a mine to compare the feed concentration and the flocculant unit consumption to the maximum settling velocity and static settling limit concentration of tailings. The influencing factors were examined, and a simple settling velocity model was obtained by regression analysis of experimental data. Tao et al. [12] studied the flocculation and sedimentation dynamics of mortar in a measuring cylinder and divided the settlement process into a disturbance zone, subsidence zone, and compaction zone. Bürgera et al. [13] studied the flocculation and sedimentation performance of five different cross section sedimentation devices with cylindrical, dispersed, and conical shapes and proposed a mathematical model of continuous settlement and concentration. Wang et al. [14] established a GA-SVM optimization prediction model for the settlement velocity of the whole tailings and optimized the prediction of the settlement velocity of the whole tailings using the genetic algorithm. Wang et al. [15] performed a flocculation sedimentation test on the influence of the type of flocculant, the concentration of pulp, and the addition amount of different chemicals on the sedimentation velocity and confirmed the effect of highmolecular-weight flocculant on accelerating particle sedimentation. Wang et al. [16] used the ultrafine tailings of a mine to investigate the three experimental factors of slurry concentration, flocculant unit consumption, and flocculant concentration and studied the influence of different factors on sedimentation velocity and concentration. Using a uniform design method under the condition of dynamic flocculation and sedimentation as well as static settlement, Wang et al. [17] used the unit solid area solid processing amount and the bottom fluid integral number as evaluation indexes to test the effects and influencing factors of tailings density. In a flocculation sedimentation experiment, Shi et al. [18] examined tailings slurry with different sand concentrations and anionic polyacrylamide with different molecular weights as flocculant, along with a certain amount of inorganic flocculant, to characterize a vertical sand silt slurry.

In the present paper, the ultrafine tailings of the Mikang Iron Mine in Fujian Province were taken as the research object. A natural sedimentation experiment was carried out on the ultrafine tailings slurry with a concentration of $30 \%$. The results showed that the natural sedimentation rate was slow and the liquid on the top was cloudy, indicating the presence of a large amount of tailings. The fine tailings were suspended on the top and did not settle readily, which had an adverse effect on the safety and stability of the tailings dam. In contrast, previous research on flocculants mostly focused on a single factor and did not analyze the sedimentation effects of various flocculants. Studying the sedimentation effect of tailings slurry under the action of various flocculants provides new insights for improving the flocculation and sedimentation effect of tailings as well as the safety and stability of tailings dams. To this end, this paper selected curing agent materials comprising polyacrylamide, polyaluminum chloride, polyferric sulfate, and polyaluminum sulfate, which are effective flocculants for the sedimentation of ultrafine tailings slurries. The optimum types and optimal dose of each of these materials were investigated separately. Then, the synergistic effect of the above four flocculants was investigated using a four-factor and three-level orthogonal experiment, and most of the four flocculants behaved better in combination. The tailings floc using the optimal ratio of flocculant was subjected to a direct shear test and permeation test to analyze the changes in mechanical properties.

\section{Physical Properties of the Ultrafine Tailings}

2.1. Composition of the Tailings Sand. The ore type in the Makeng mining area is mainly magnetite. The tailings sand from the Makeng iron ore was analyzed by X-ray fluorescence spectroscopy (XRF) and was mainly composed of $\mathrm{SiO}_{2}, \mathrm{CaO}, \mathrm{Fe}_{2} \mathrm{O}_{3}, \mathrm{MgO}, \mathrm{Al}_{2} \mathrm{O}_{3}$, and other components. The composition is shown in Table 1.

The tailings sand was subjected to X-ray diffraction (XRD) analysis. The main mineral components of tailings sand were calcite, andradite, quartz, fluorite, and titanite. The specific content is shown in Figure 1.

2.2. Tailings Sand Particle Screening Experiment. The tailings sand particles were passed through a particle size screener, and the particle grading curve of the tailings sand is shown in Figure 2 .

It can be seen from the figure that the fraction of the ultrafine tailings sand with particles less than $0.074 \mathrm{~mm}$ in size accounted for $51.2 \%$ of the total, which indicates that they met the definition of ultrafine tailings.

2.3. Ultrafine Tailings Sand Direct Shear Test. The ultrafine tailings sand samples were prepared according to the standard method for geotechnical experiments before solidification, and then the direct shear test was carried out. The results of the direct shear test are shown in Figures 3 and 4.

From Figures 3 and 4, the cohesive force $c$ of the ultrafine tailings sand is $27 \mathrm{kPa}$ and the internal friction angle $\varphi$ is $25.53^{\circ}$. 
TABLE 1: Chemical composition and content of ultrafine tailings.

\begin{tabular}{lccccccc}
\hline Chemical composition & $\mathrm{SiO}_{2}$ & $\mathrm{CaO}$ & $\mathrm{Fe}_{2} \mathrm{O}_{3}$ & $\mathrm{MgO}$ & $\mathrm{Al}_{2} \mathrm{O}_{3}$ & $\mathrm{MnO}$ & $\mathrm{Others}$ \\
\hline Content (\%) & 37.07 & 26.06 & 18.47 & 9.00 & 3.60 & 2.07 & 3.73 \\
\hline
\end{tabular}

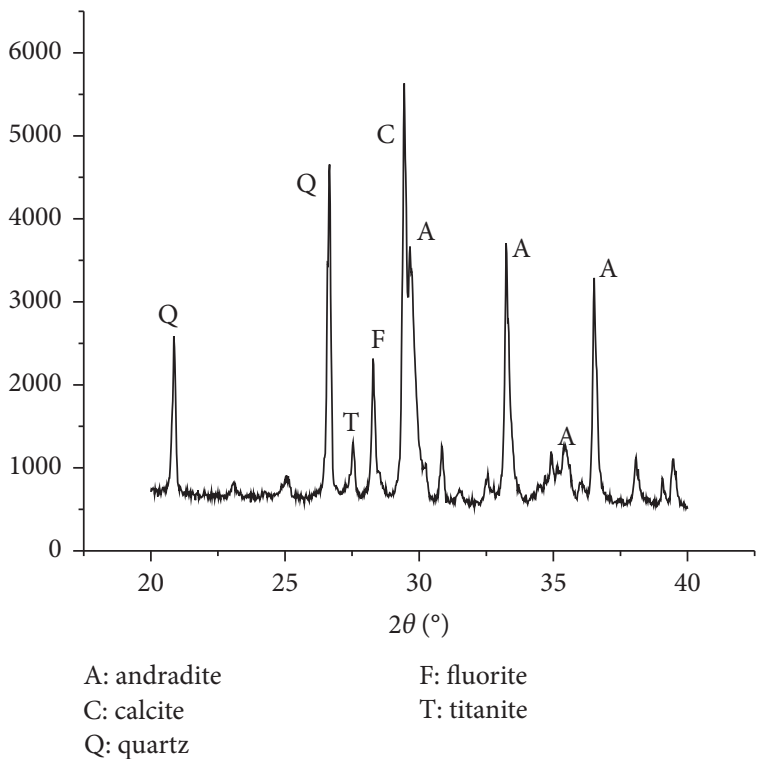

FIGURE 1: XRD spectrum of tailings.

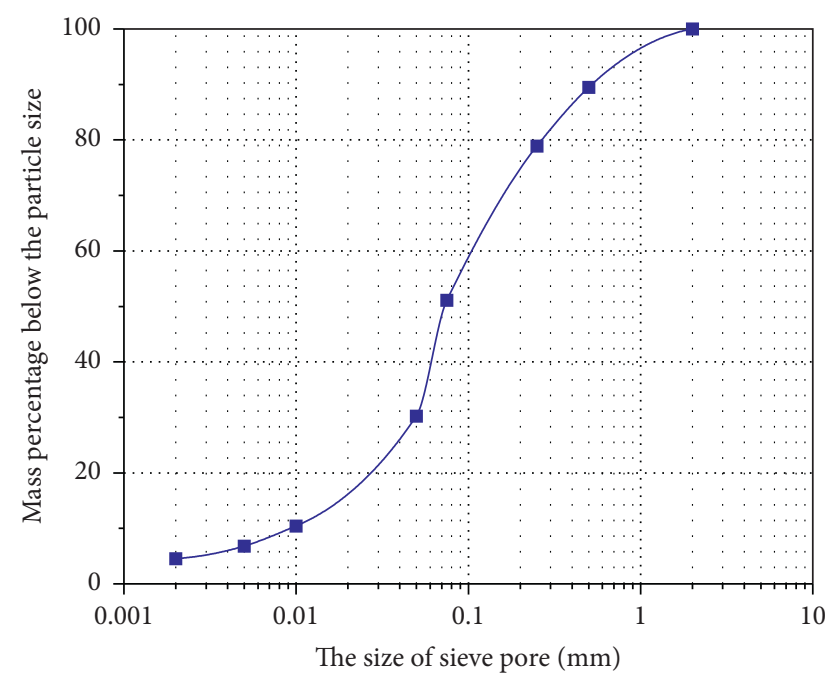

FIgURE 2: Grading curve of tailings.

2.4. Determination of the Permeability Coefficient of Tailings. Preliminary experiments indicated that the ultrafine tailings sand used in this paper had a large permeability coefficient and that a constant head experiment could be used. The experimental results are shown in Table 2.

According to Table 2, the permeability coefficient of the ultrafine tailings is $4.03 e-05 \mathrm{~cm} / \mathrm{s}$.

\section{Experimental Method}

This paper investigated curing agent materials comprising polyacrylamide, polyaluminum chloride, polyferric sulfate,

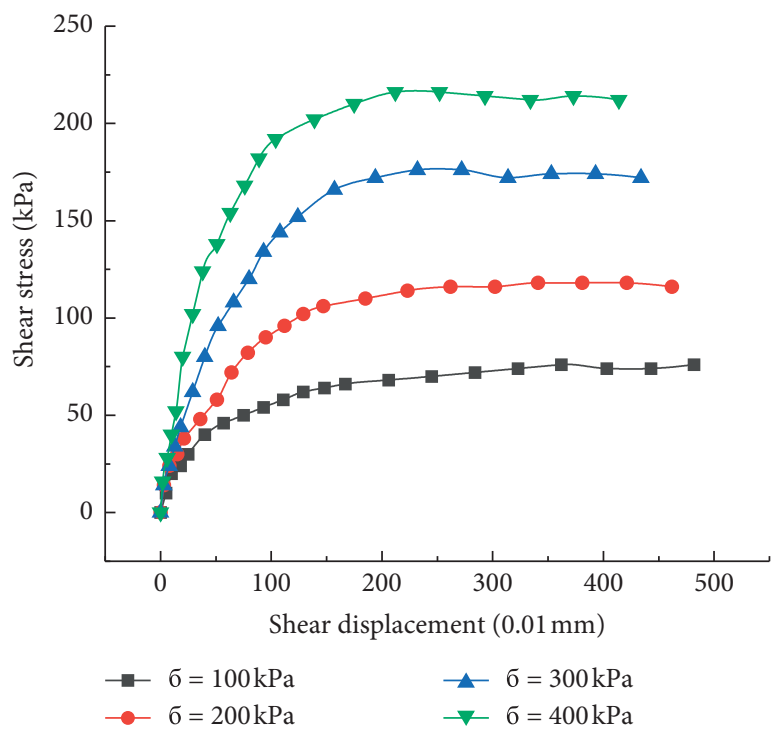

Figure 3: The curve of shear displacement and shear stress.

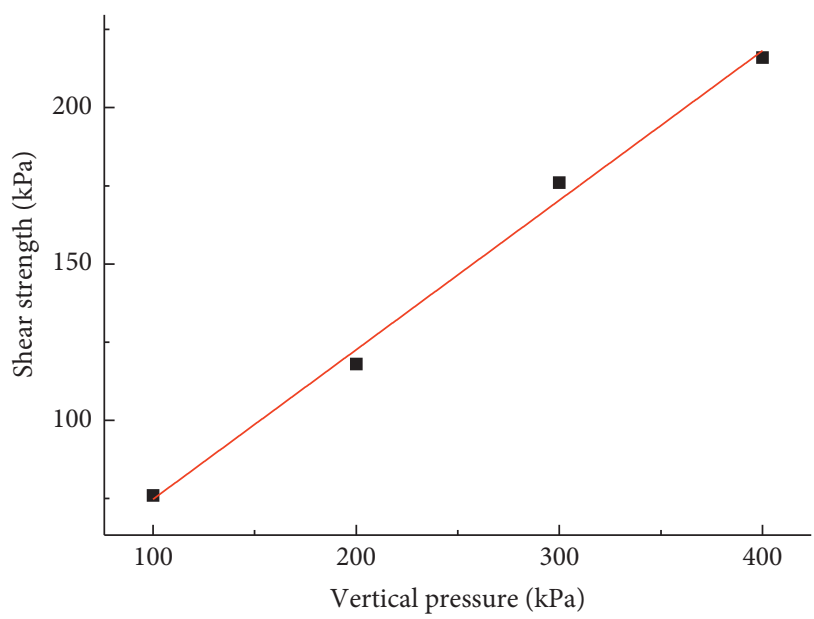

FIgURE 4: The curve of vertical pressure and shear strength.

and polyaluminum sulfate, which are effective flocculants for the sedimentation of ultrafine tailings slurries. A sedimentation experiment with a $1 \mathrm{~L}$ volume of tailings slurry in the measuring cylinder was carried out. The experimental process was as follows:

(1) In a single-factor flocculation experiment, the effects of different ion types, different molecular weights, and different addition amounts on the flocculation sedimentation results were tested for polyacrylamide. Different molecular contents and different admixtures were tested for polyaluminum chloride. The effects of different additions on the results of condensate sedimentation were investigated for polyferric sulfate and polyaluminum sulfate. 
TABLe 2: Permeation test data of ultrafine tailings.

\begin{tabular}{lcccccc}
\hline $\begin{array}{l}\text { Test } \\
\text { number }\end{array}$ & $\begin{array}{c}\text { Water head } \\
\text { height } h(\mathrm{~cm})\end{array}$ & $\begin{array}{c}\text { Time } \\
t(\mathrm{~s})\end{array}$ & $\begin{array}{c}\text { Flux } \\
Q(\mathrm{~mL})\end{array}$ & $\begin{array}{c}\text { Penetrating } \\
\text { length } L(\mathrm{~cm})\end{array}$ & $\begin{array}{c}\text { Area } \\
A\left(\mathrm{~cm}^{2}\right)\end{array}$ & $\begin{array}{c}\text { Permeability } \\
\text { coefficient } k(\mathrm{~cm} / \mathrm{s})\end{array}$ \\
\hline 1 & 133.5 & 1200 & 45.9 & 4 & 30 & $3.82 e-05$ \\
2 & 139.5 & 1200 & 53.2 & 4 & 30 & $4.24 e-05$ \\
\hline
\end{tabular}

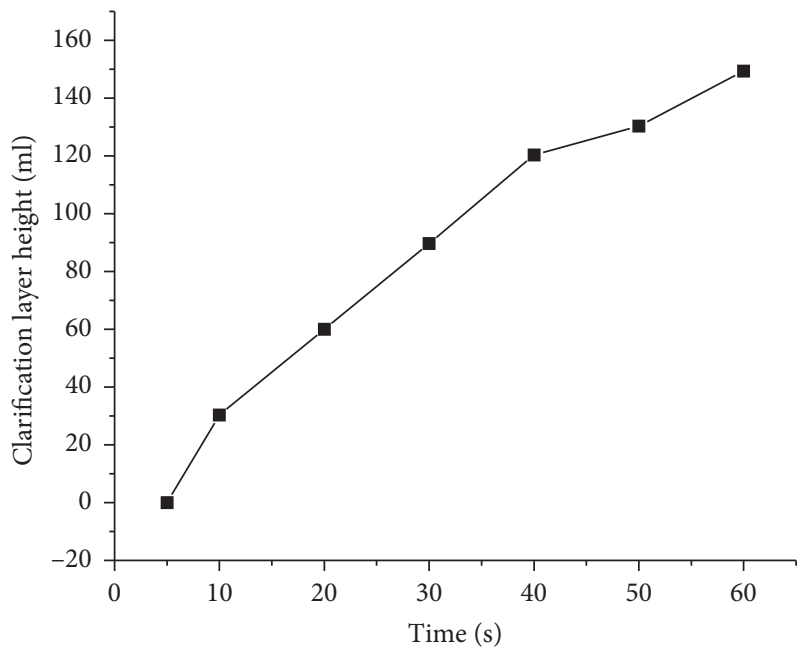

(a)

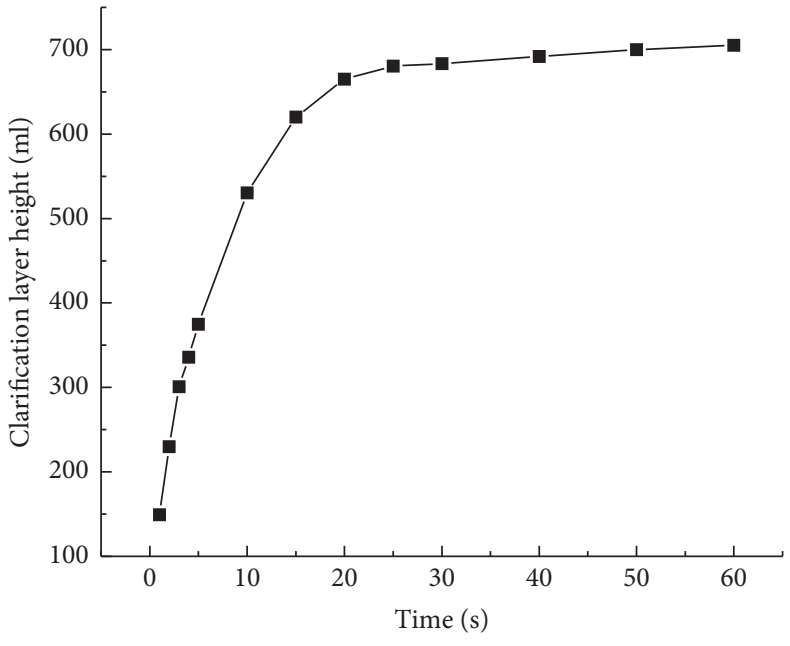

(b)

FIgURE 5: The curve of tailing pulp natural sedimentation clarification layer height and time. (a) The curve in one minute. (b) The curve in one hour.

(2) In an orthogonal experiment, namely, a four-factor, three-level orthogonal experiment, the synergistic effect of the above four flocculants was investigated, and the optimal ratio of the four flocculants was determined when the flocculation was jointly exerted.

(3) In a comparative experiment of mechanical properties, a direct shear test and permeation test were carried out on the tailings floc after the addition of the optimal proportion flocculant. The obtained data were compared with the tailings sand sample without flocculant, and the mechanical properties of the tailings after flocculation were analyzed.

\section{Single-Factor Flocculant Sedimentation Experiment}

An ultrafine tailings slurry with a mass concentration of $30 \%$ was prepared. Immediately after stirring, a certain concentration of flocculant was added, and the mixture was stirred for 30 seconds with a stir bar. The sedimentation of the tailings slurry was allowed to stand still, and the height of the supernatant was determined separately.

\subsection{The Sedimentation Test of Tailings Sand in the Natural} State without Adding Flocculant. A time-lapse image of the natural sedimentation of the tailings slurry is shown in Figure 5. Because the sedimentation effect occurs quickly, the height of the clear layer changed within a few seconds. After the flocculant was added, the sedimentation was more rapid and needed to be drawn for $1 \mathrm{~min}$. It took between $1 \mathrm{~min}$ and $60 \mathrm{~min}$ to form a clear layer on top.
It can be seen from the figure that the natural sedimentation speed of the tailings slurry was slow, the supernatant liquid was turbid, and a large amount of fine tailings were still suspended in the supernatant and did not settle readily. Typically, it takes approximately 2 hours for fine tailings to settle, and the supernatant is clear and unstable; the tailings can be easily resuspended by external forces. The natural sedimentation of the tailings slurry was used as a control group, and then the sedimentation of the tailings slurry with the flocculant was compared with the natural sedimentation control.

4.2. Analysis of the Sedimentation Effect of Polyacrylamide. In this paper, the effect of polyacrylamide on the settling of tailings was investigated. The effects of different ion types, molecular weights, and doses on the sedimentation of $30 \%$ tailings slurry were investigated.

4.2.1. Effect of the Polyacrylamide Ion Type on the Sedimentation Effect. Polyacrylamide with 12 million molecular weight was selected, and the amount of pulp was $3 \%$. The effects of cation, anion, and nonionic polyacrylamides on the sedimentation of ultrafine tailings were investigated. The experimental results show that when polyacrylamide was used as a flocculant, the sedimentation speed of the tailings slurry was obviously improved. In a short time, the ultrafine tailings slurry formed a layered structure, but the supernatant liquid was slightly turbid. It can be seen from Figure 6 that the cationic polyacrylamide had the best sedimentation 


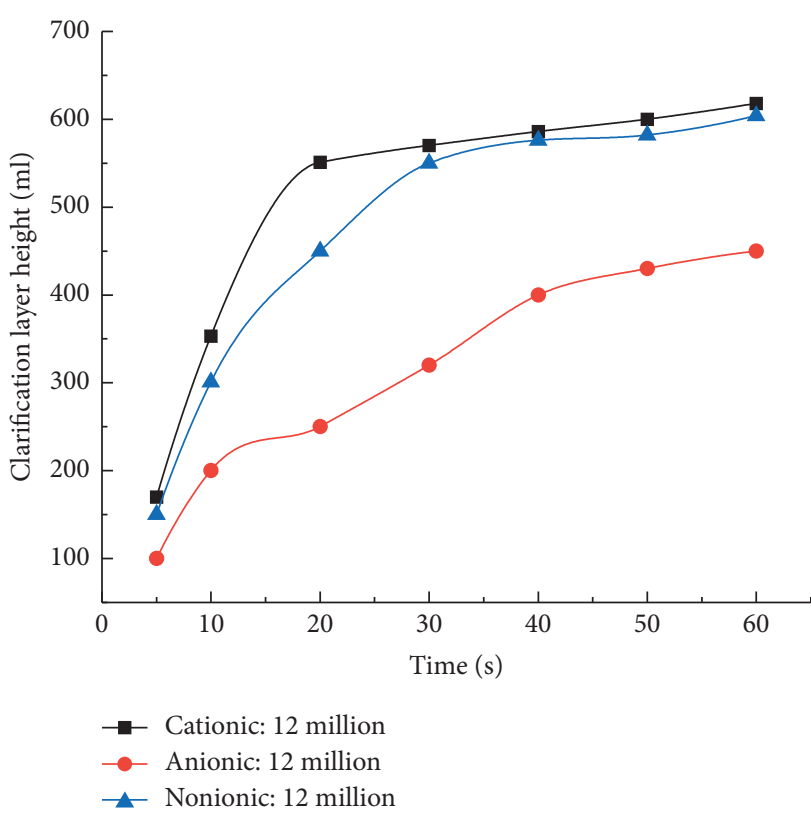

(a)

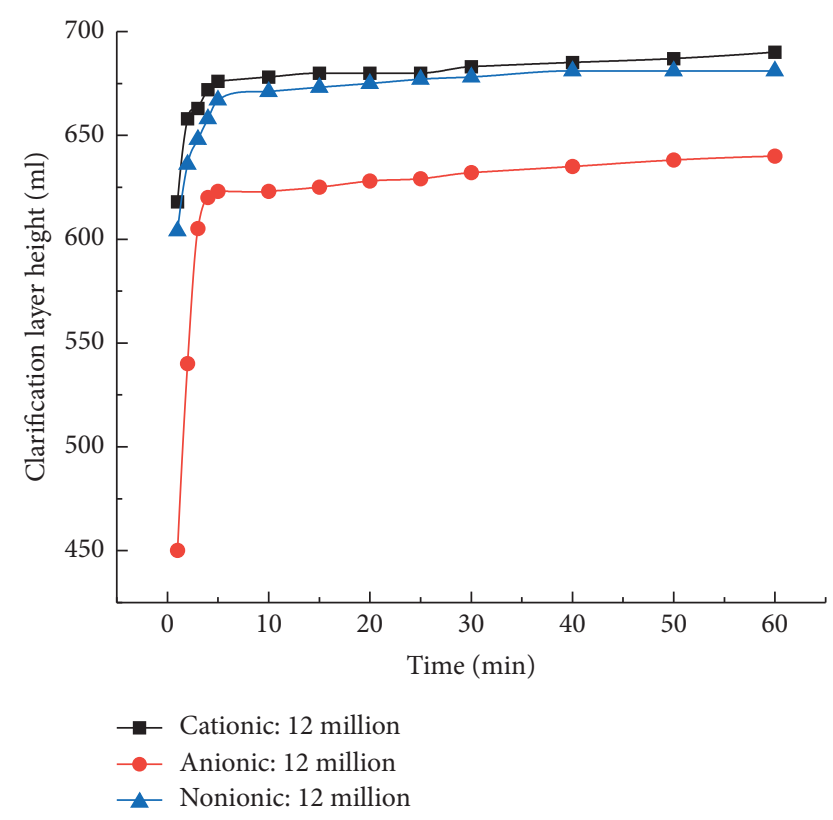

(b)

Figure 6: The effect of different ionic types of polyacrylamide on clarification layer height. (a) The curve in one minute. (b) The curve in one hour.

effect on the tailings slurry, followed by the nonionic and anionic slurries.

4.2.2. Effect of the Molecular Weight of Polyacrylamide on the Sedimentation Effect. Cationic polyacrylamide with molecular weights of 10 million, 12 million, 15 million, and 18 million was added to the tailings slurry in an amount of $3 \%$, and its effects on the sedimentation of the tailings slurry were investigated.

Figure 7 shows that the sedimentation effect of the tailings gradually decreased with increasing molecular weight.

4.2.3. Effect of the Polyacrylamide Dose on the Sedimentation Effect. The effects of $2 \%, 4 \%$, and $5 \%$ cationic polyacrylamide with a molecular weight of 10 million on the tailings sedimentation effect were investigated. The effects of different amounts of polyacrylamide on the height of the slurry clearing layer are shown in Figure 8.

It can be seen in Figure 8 that the sedimentation effect of the tailings increased with increasing polyacrylamide content, with an initial sharp increase followed by a more gradual increase. Therefore, the optimum amount of cationic polyacrylamide with a molecular weight of 10 million is $3 \%$ of the mass of the ultrafine tailings slurry.

\subsection{Analysis of the Flocculation Results of Polyaluminum Chloride}

4.3.1. Effect of the Polyaluminum Chloride Content on the Sedimentation Effect. Polyaluminum chloride with a content of 28 and 30 was selected, and the concentration of the flocculant was $5 \%$. The experimental results showed that when polyaluminum chloride was used as a flocculant, the sedimentation effect was excellent, the supernatant was very clear, and the bottom floc structure was large. The flocculant was loose, did not stick to the wall, and was easy to handle. However, the concentration of polyaluminum chloride at $5 \%$ did not clearly increase the sedimentation speed of the tailings slurry. The flocculation sedimentation within one minute was slow and then gradually accelerated. The effect of promoting sedimentation is shown in Figure 9.

It can be seen from Figure 9 that the polyaluminum chloride with a content of 28 is better than that with a content of 30 .

4.3.2. Effect of the Amount of Polyaluminum Chloride on the Sedimentation Effect. The effect of the amount of polyaluminum chloride with a content of 28 on the sedimentation of the tailings slurry was investigated further. The experimental results are shown in Figure 10. Compared with the natural sedimentation of the slurry, the sedimentation rate of the polyaluminum chloride was significantly improved. When the dose was $0.1 \%$, the polyaluminum chloride with a content of 28 had the best flocculation effect of the polyaluminum chloride samples considered in this study.

4.4. Analysis of the Flocculation Results of Polymeric Ferric Sulfate. The experimental data show that after the addition of polyferric sulfate, the sedimentation speed of the original slurry obviously improved, the supernatant liquid was turbid, the reaction was intense, a large number of bubbles 


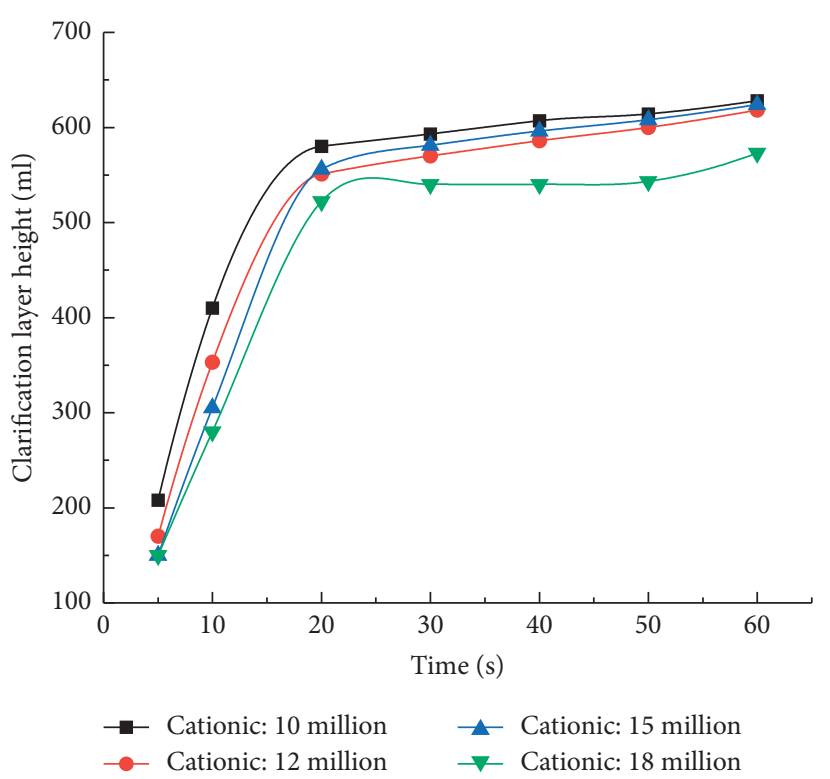

(a)

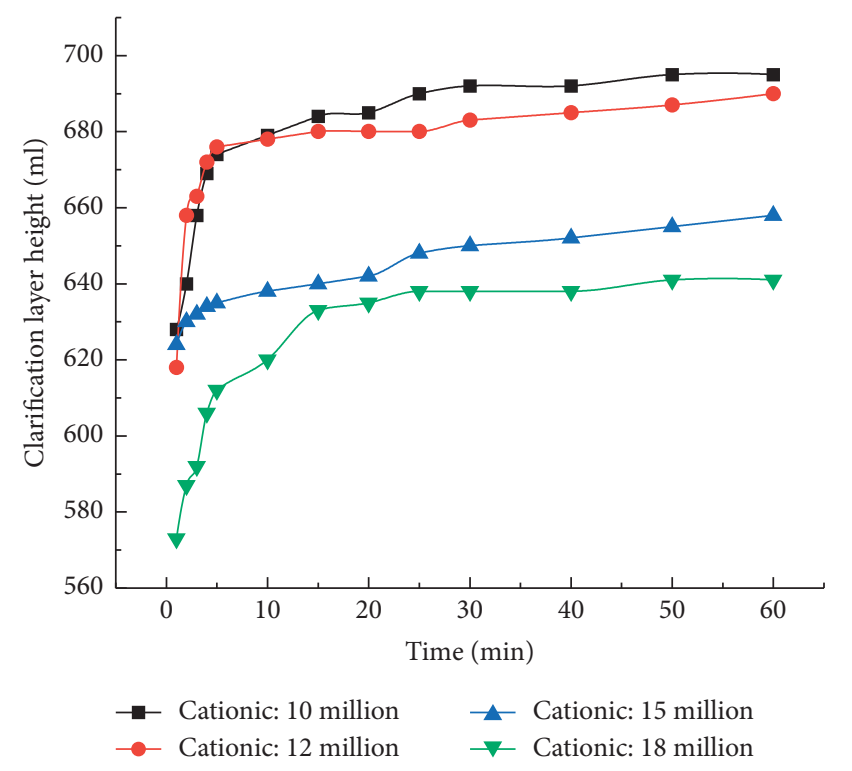

(b)

FIGURE 7: The effect of different molecular weights of polyacrylamide on clarification layer height. (a) The curve in one minute. (b) The curve in one hour.

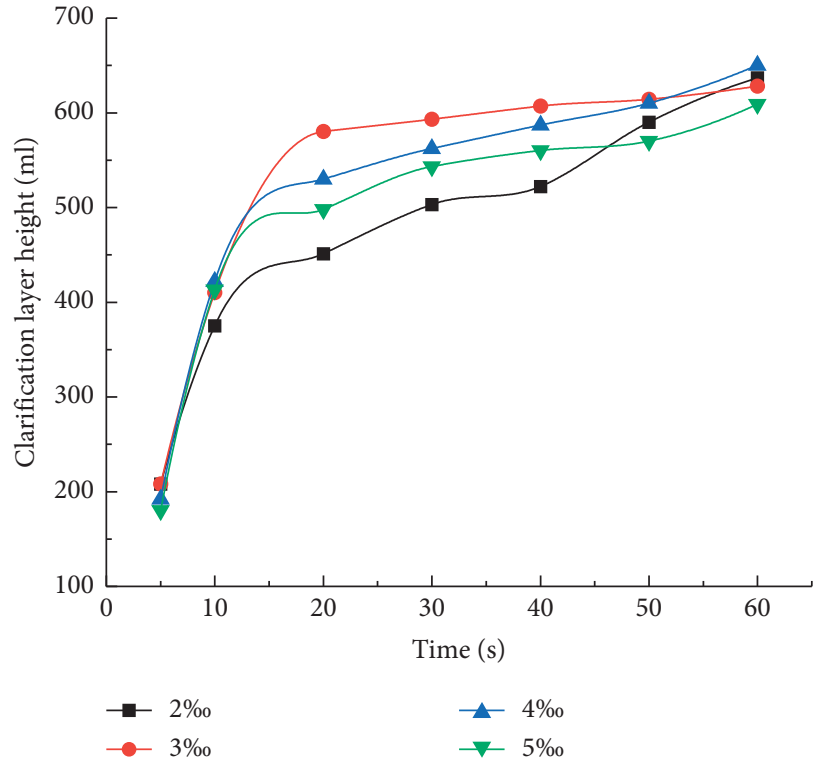

(a)

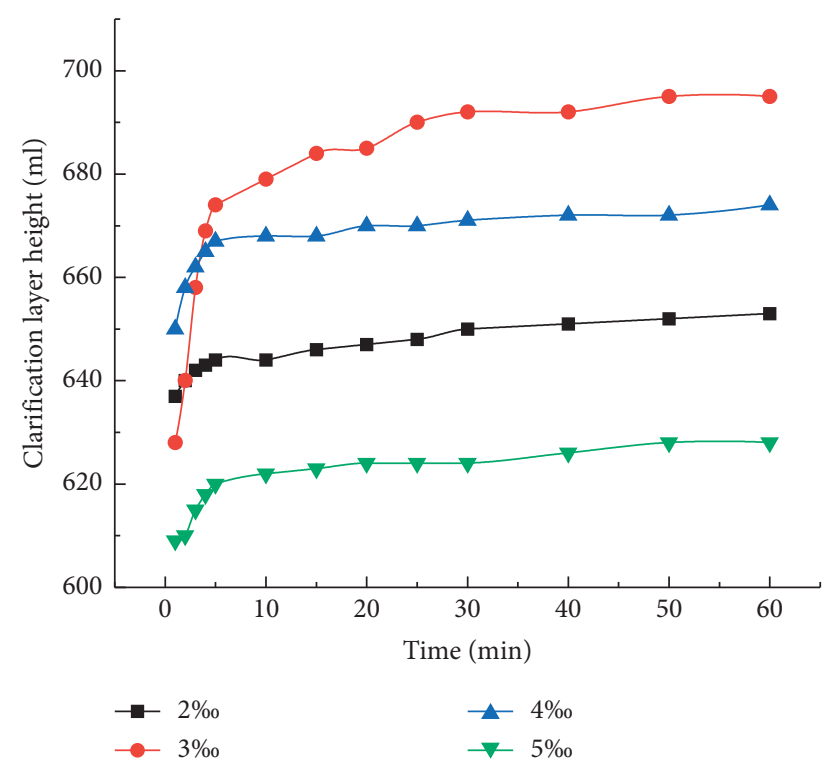

(b)

Figure 8: The effect of different mixing amounts of polyacrylamide on clarification layer height. (a) The curve in one minute. (b) The curve in one hour.

were generated, and the formed flocs were small and dense. The effects of flocculation and sedimentation of polymeric ferric sulfate at different concentrations are shown in Figure 11 .

It can be concluded from Figure 11 that the flocculation effect of the polymerized ferric sulfate was the best for this material when the dose was $1 \%$.
4.5. Polyaluminum Sulfate Flocculation Results. The experimental results show that when polyaluminum sulfate was used as the flocculant, the supernatant of the ultrafine tailings slurry was relatively clear and the sedimentation speed was obviously improved. The flocculated sedimentation of polyaluminum sulfate at different concentrations was carried out, and the results are shown in Figure 12. 


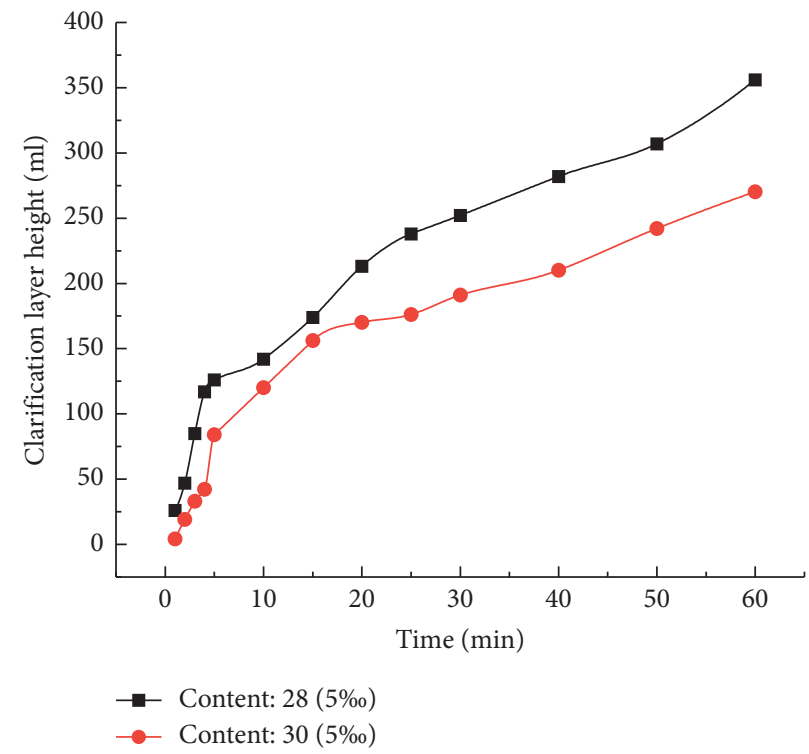

Figure 9: The effects of different contents of polyaluminum chloride on clarification layer height.

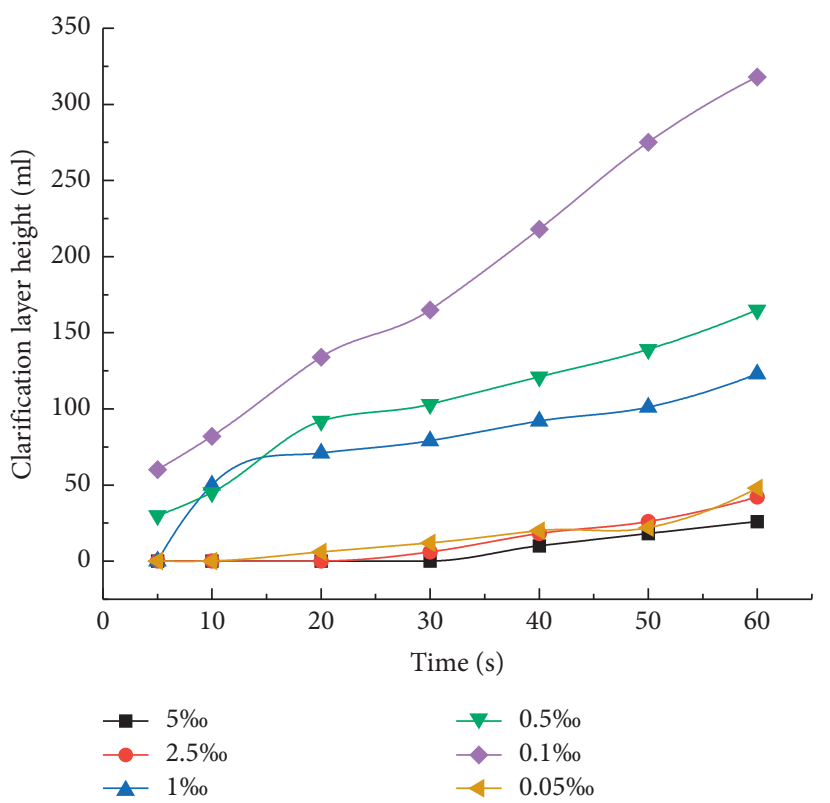

(a)

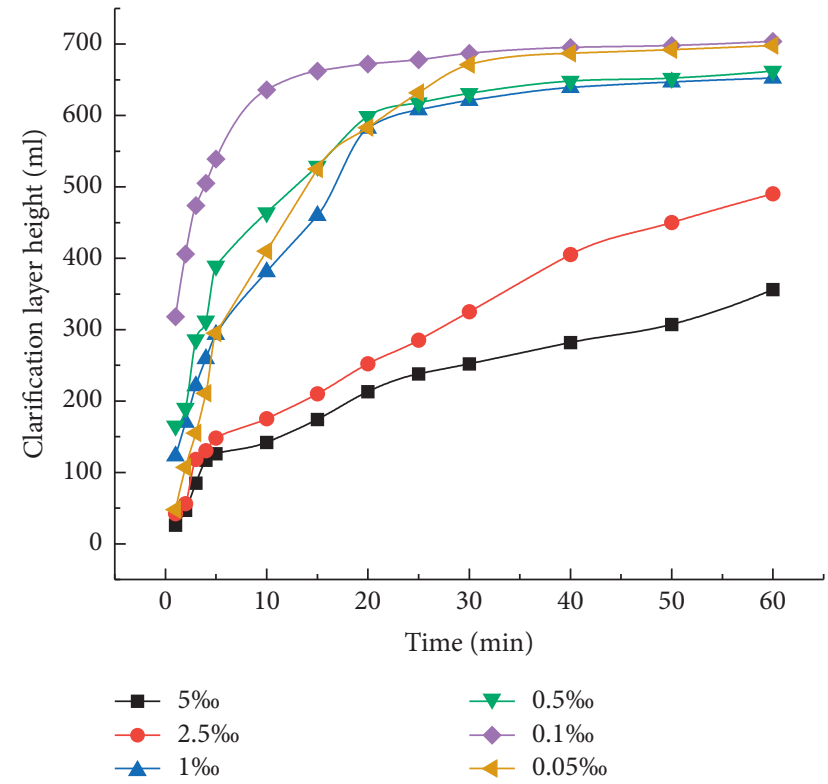

(b)

FIGURE 10: The effects of different mixing amounts of polyaluminum chloride on clarification layer height. (a) The curve in one minute. (b) The curve in one hour.

It can be seen from Figure 12 that the addition of polyaluminum sulfate can effectively increase the sedimentation speed of an ultrafine tailings slurry and the flocculation effect was best for this material when the dose was $1 \%$.

\section{Flocculant Orthogonal Test}

5.1. Orthogonal Experimental Design. Through the above four groups of single-factor experiments, the types and optimal doses of the four flocculants of polyacrylamide, polyaluminum chloride, polyaluminum sulfate, and polyferric sulfate were determined. To investigate the synergy among these materials, the effects of the four flocculants on tailings settlement were investigated using orthogonal experiments. The experimental design is shown in Table 3.

5.2. Orthogonal Test Results. Through the nine experiments referred to as M1-M9, the relationship between a clear layer of the tailings slurry and the time was obtained under different doses (Figure 13). 


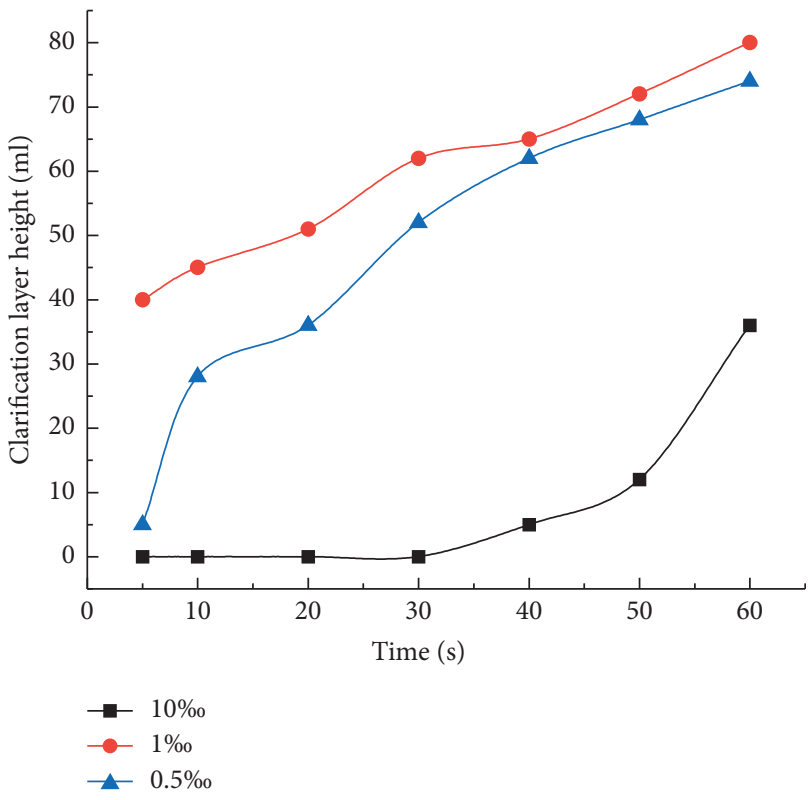

(a)

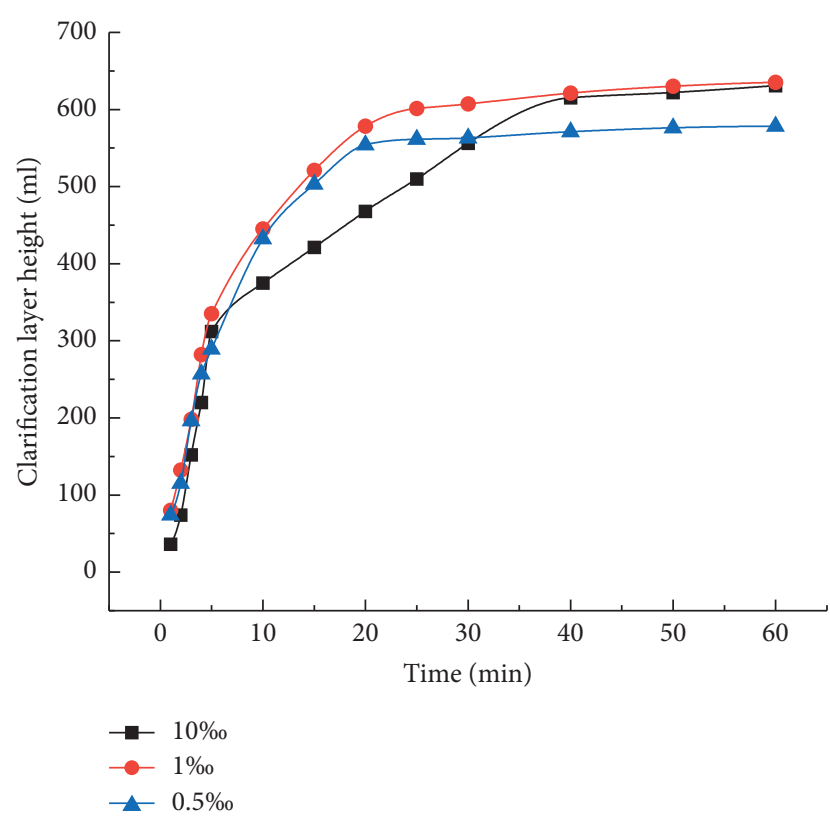

(b)

FIGURE 11: The effects of different mixing amounts of polymeric ferric sulfate on clarification layer height. (a) The curve in one minute. (b) The curve in one hour.

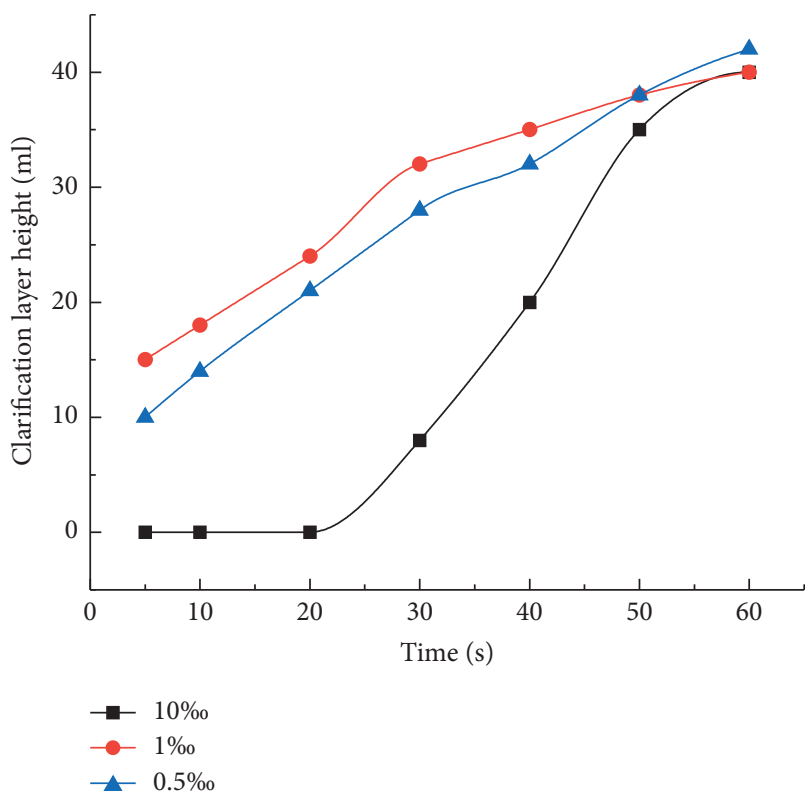

(a)

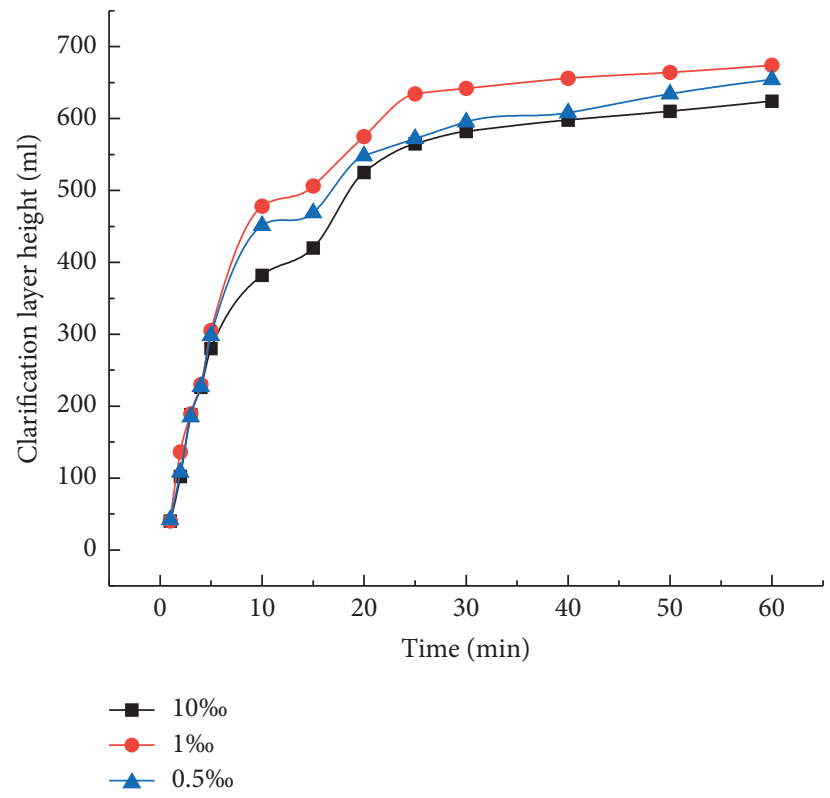

(b)

Figure 12: The effects of different mixing amounts of polyaluminum sulfate on clarification layer height. (a) The curve in one minute. (b) The curve in one hour.

It can be seen from Figure 13 that the height of the clarification layer changed with time. The height of the initial clarification layer increased rapidly with time, and then it stabilized at the later stage. The trend of the logarithmic function is shown in Table 4 .

It can be seen from the table that $R^{2}$ is close to 1 and the significance is less than 0.05 , indicating that the function fitting was accurate and the fitting result is a logarithmic function. In the process of sedimentation of the tailings slurry, the relationship between the height of the clearing layer and time is a logarithmic function. The nine logarithmic functions can be determined by the constants $c$ and $b$. The function can be expressed as follows: 
TABLe 3: Orthogonal experimental design.

\begin{tabular}{lcccc}
\hline No. & Polyacrylamide (\%o) & Polyaluminum chloride (\%o) & Polyaluminum sulfate (\%o) & Polyferric sulfate (\%o) \\
\hline 1 & 2 & 0.05 & 0.5 & 0.5 \\
2 & 2 & 0.1 & 1 & 1 \\
3 & 2 & 0.15 & 1.5 & 1.5 \\
4 & 3 & 0.05 & 1.5 & 0.5 \\
5 & 3 & 0.1 & 0.5 & 1.5 \\
6 & 3 & 0.15 & 0.5 & 1.5 \\
7 & 4 & 0.05 & 1 & 1.5 \\
8 & 4 & 0.1 & 0.5 \\
9 & 4 & 0.15 & 1 & 0.5 \\
\hline
\end{tabular}

The dosage is the mass percentage of ultrafine tailings slurry, and the concentration of ultrafine tailings slurry is $30 \%$.

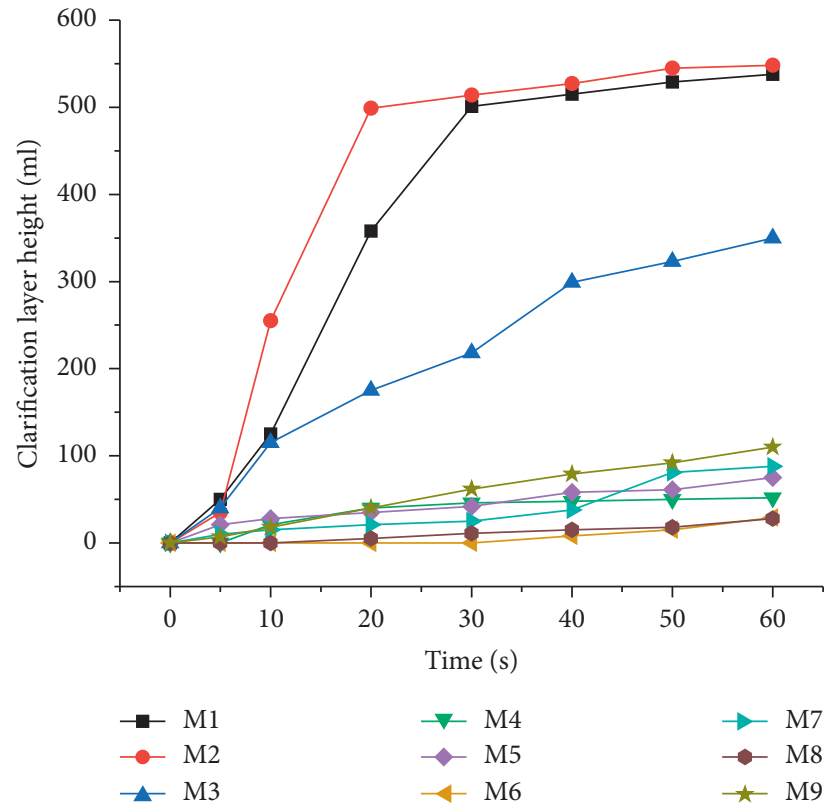

(a)

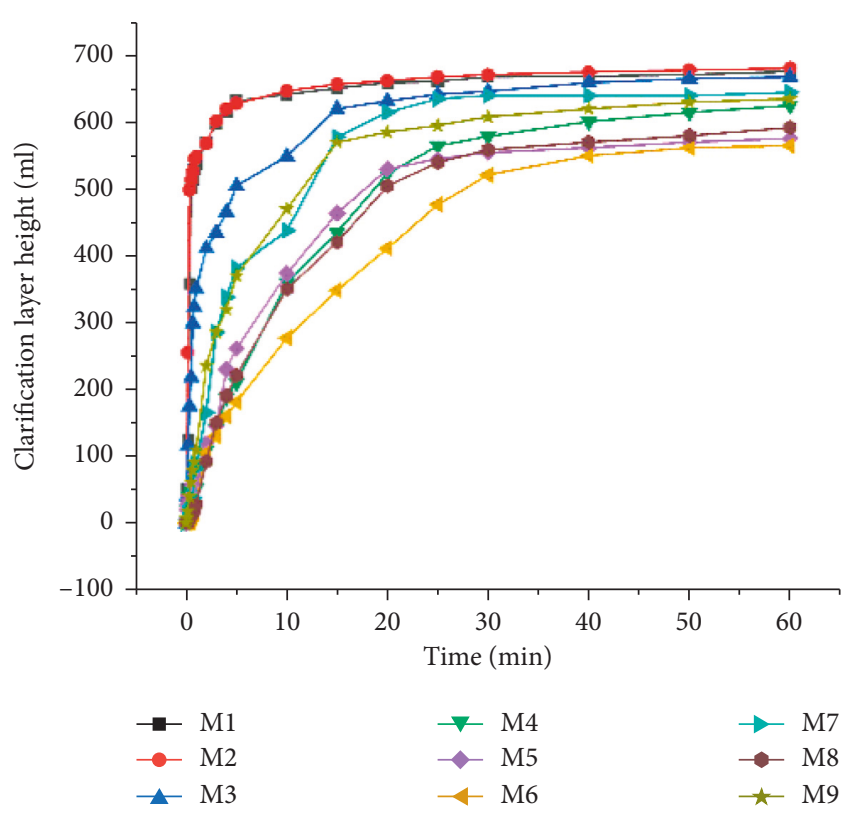

(b)

Figure 13: The curve of tailing pulp clarification layer height and time in orthogonal experiments. (a) The curve in one minute. (b) The curve in one hour.

TABLE 4: Regression analysis.

\begin{tabular}{lccccc}
\hline Group & Fitting equation & $R^{2}$ & $F$ & Significant & Constant $(c)$ \\
\hline M1 & Log & 0.922 & 130.668 & 0.000 & 559.855 \\
M2 & Log & 0.940 & 172.136 & 0.000 & 562.790 \\
M3 & Log & 0.973 & 391.451 & 0.000 & 358.447 \\
M4 & Log & 0.975 & 433.169 & 0.000 & -3.200 \\
M5 & Log & 0.965 & 303.017 & 0.000 & 41.760 \\
M6 & Log & 0.976 & 448.992 & 0.000 & -17.217 \\
M7 & Log & 0.951 & 212.197 & 0.000 & 116.487 \\
M8 & Log & 0.981 & 572.994 & 0.000 & -2.965 \\
M9 & Log & 0.967 & 319.098 & 0.000 & 143.158 \\
\end{tabular}

$$
h=c+b * \ln t
$$

where $h$ is the height of the clearing layer and $t$ is the settling time.

It was empirically found that when the height of the clarification layer was close to $90 \%$ of the height after 1 hour, the slope was low; thus, the calculation of the settling speed of each group to $90 \%$ of the height at 1 hour can represent the sedimentation velocity of the tailings slurry. The results are shown in Table 5.

As shown in Table 5, group M2 had the fastest sedimentation rate. The comprehensive experimental phenomena 
TABLE 5: Visual analysis of orthogonal experiment results.

\begin{tabular}{lccccc}
\hline Group & Polyacrylamide & Polyaluminum chloride & Polyaluminum sulfate & Polyferric sulfate & Clarification layer height (1 hour) \\
\hline M1 & 2 & 0.05 & 0.5 & 0.5 & 1 \\
M2 & 2 & 0.1 & 1 & 1.5 & 676 \\
M3 & 2 & 0.15 & 1 & 1.5 & 668 \\
M4 & 3 & 0.05 & 1.5 & 0.5 & 625 \\
M5 & 3 & 0.1 & 0.5 & 1 & 576 \\
M6 & 3 & 0.15 & 1.5 & 1 & 565 \\
M7 & 4 & 0.05 & 0.5 & 1.5 & 645 \\
M8 & 4 & 0.15 & 1 & 0.5 & 592 \\
M9 & 4 & 0.1 & 611.000 & 629.000 & 635 \\
\hline$k_{1}$ & 675.000 & 648.667 & 647.000 & 630.333 & 628.333 \\
$k_{2}$ & 588.667 & 616.333 & 629.667 & 2.000 & \\
$k_{3}$ & 624.000 & 622.667 & 36.000 & & \\
$R$ & 86.333 & 32.334 & & &
\end{tabular}

TABLE 6: Single-factor regression analysis.

\begin{tabular}{lccc}
\hline Factor & Square of deviance & $F$ ratio & $F$ critical values \\
\hline Polyacrylamide & 11302.889 & 1816.536 & 4.46 \\
Polyaluminum chloride & 1761.556 & 283.107 & 4.46 \\
Polyaluminum sulfate & 1944.889 & 312.571 & 4.46 \\
\hline
\end{tabular}

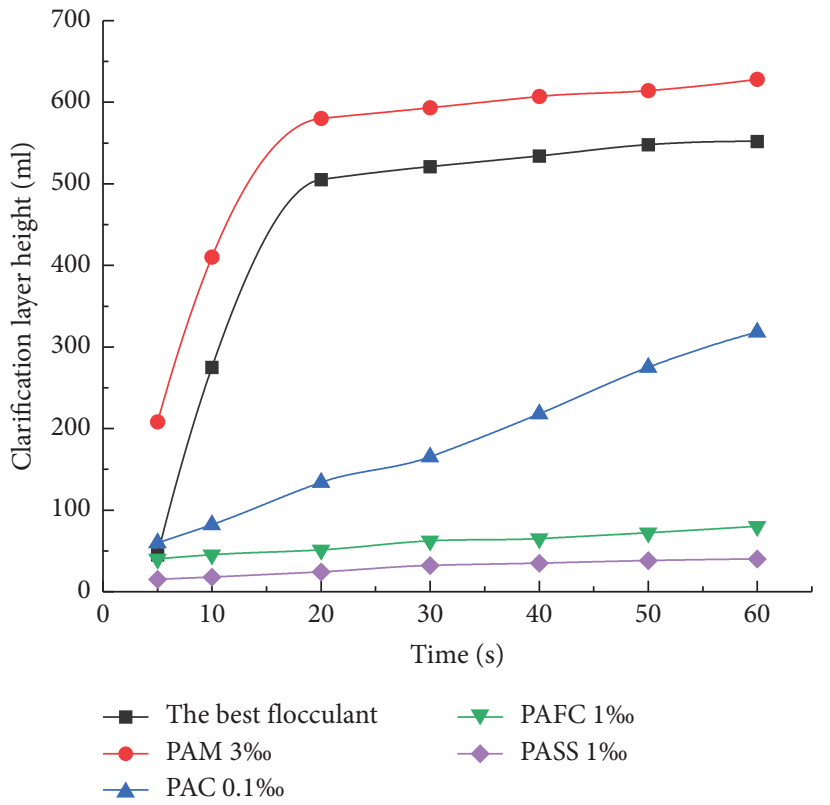

(a)

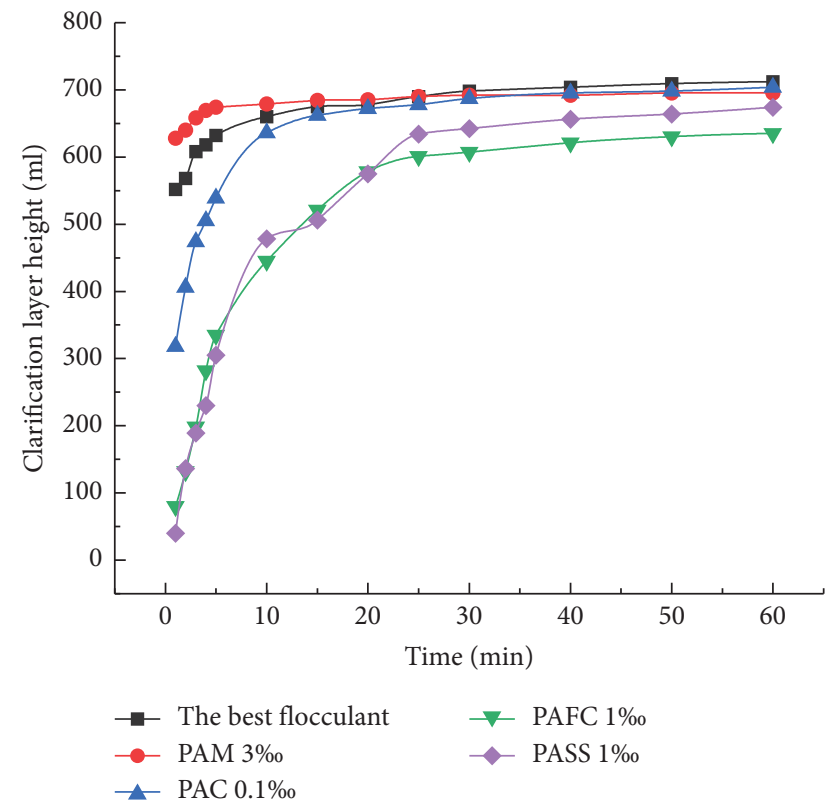

(b)

Figure 14: The curve of tailing pulp clarification layer height and time. (a) The curve in one minute. (b) The curve in one hour.

showed that the supernatant of the M2 group was clearer than that of the other groups during the experiment.

The optimum level was determined by the average value of each flocculant. Polyacrylamide was level 1, polyaluminum chloride was level 1 , polyaluminum sulfate was level 2, and polyferric sulfate was level 2; that is, the optimal combination was A1B1C2D2. In other words, the optimum combination consisted of a $2.0 \%$ dose of cationic polyacrylamide with a molecular weight of 10 million, $0.05 \%$ polyaluminum chloride with a content of $28,1.0 \%$ polyaluminum sulfate, and $1.0 \%$ polymeric ferric sulfate.

As shown in Table 6, the size of the $F$ ratio reflects the influence of various factors; the order of influence of each flocculant on the sedimentation velocity of the tailings slurry was $\mathrm{A}>\mathrm{C}>\mathrm{B}>\mathrm{D}$. 


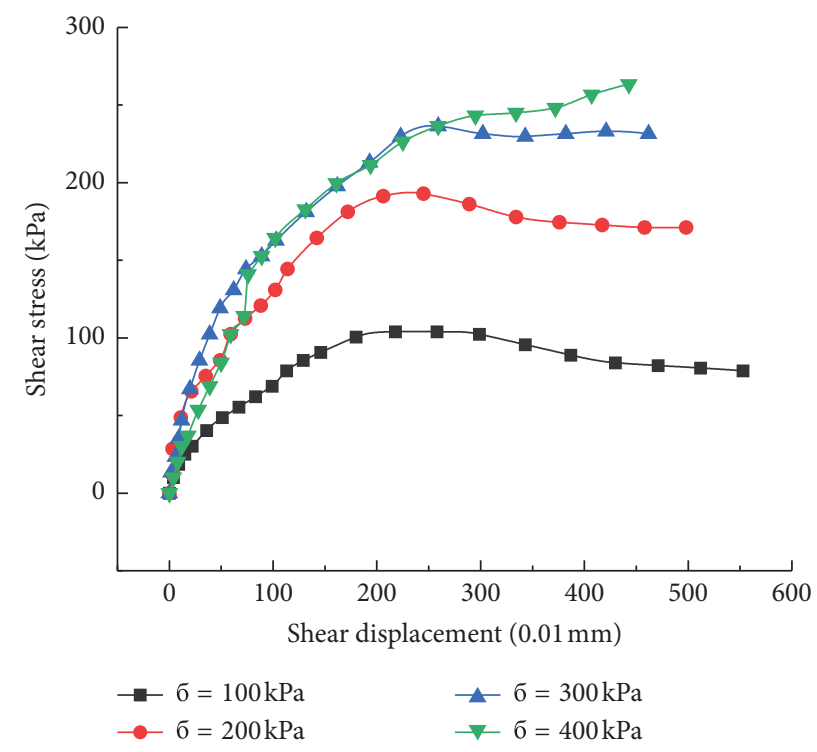

Figure 15: The curve of shear displacement stress.

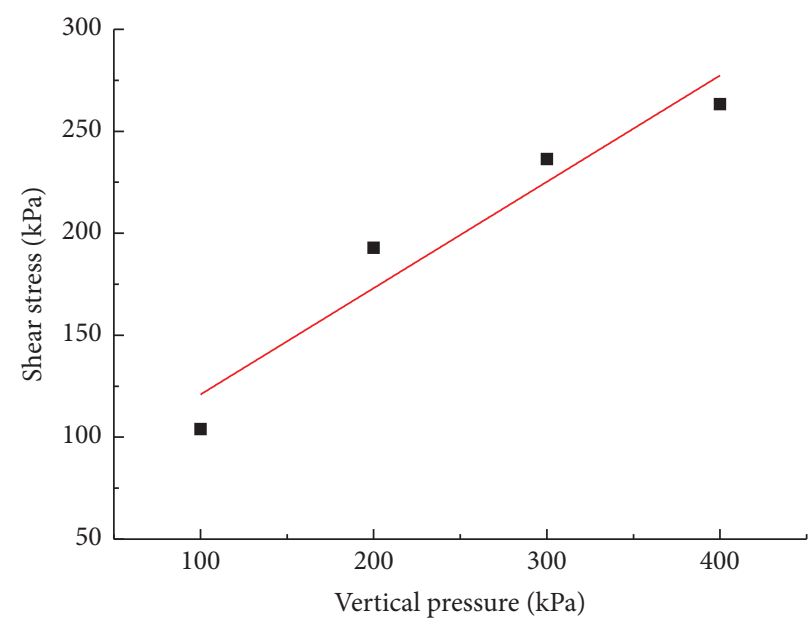

FIGURE 16: The curve of vertical pressure and shear strength.

Table 7: Permeation test data of ultrafine tailings with the addition of the optimal ratio flocculant.

\begin{tabular}{lcccccc}
\hline $\begin{array}{l}\text { Test } \\
\text { number }\end{array}$ & $\begin{array}{c}\text { Water head } \\
\text { height } h(\mathrm{~cm})\end{array}$ & $\begin{array}{c}\text { Time } \\
t(\mathrm{~s})\end{array}$ & $\begin{array}{c}\text { Flux } \\
Q(\mathrm{~mL})\end{array}$ & $\begin{array}{c}\text { Penetrating } \\
\text { length } L(\mathrm{~cm})\end{array}$ & $\begin{array}{c}\text { Area } \\
A\left(\mathrm{~cm}^{2}\right)\end{array}$ & $\begin{array}{c}\text { Permeability } \\
\text { coefficient } k(\mathrm{~cm} / \mathrm{s})\end{array}$ \\
\hline 1 & 129.9 & 20 & 126.0 & 4 & 30 & $1.08 e-04$ \\
2 & 132.2 & 20 & 144.0 & 4 & 30 & $1.21 e-04$ \\
3 & 131.7 & 20 & 144.0 & 4 & 30 & $1.21 e-04$ \\
\hline
\end{tabular}

5.3. Analysis of the Optimal Ratio Settlement Effect. The tailing slurry was subjected to sedimentation experiments using the optimal scheme A1B1C2D2, and the results were compared with the best effects of the four individual flocculants. The results are shown in Figure 14.

For the optimal combination and polyacrylamide, the sedimentation speed of the tailings slurry was significantly faster in the first minute than for the other groups, but the optimal combination speed was slightly slower than when the polyacrylamide acted alone at $1 \mathrm{~h}$. Among the optimal combination and polyacrylamide, the sedimentation velocity was almost flat, but the supernatant was obviously clearer when the tailings slurry settled under the optimal combination. This finding indicated that the combined effect of the optimal combination was stronger than the effect of the individual flocculants acting alone. 


\section{Changes in the Mechanical Properties of Ultrafine Tailings after Composite Flocculation}

The flocculant adsorbed the tailings particles and accelerated the sedimentation rate of the tailings; this inevitably changed the internal structure of the tailings flocs and the bonding state between the particles. The cohesion, internal friction angle, and permeability coefficient were impacted. The dry density test, direct shear test, and permeation test were carried out on the tailings floc after the best proportion of flocculant was added. The experimental results are shown in Figures 15 and 16 and Table 7.

It can be concluded from Figures 15 and 16 and Table 7 that the tailings floc cohesive force $c$ after the addition of the optimal proportion flocculant was $68.757 \mathrm{kPa}$, the internal friction angle $\varphi$ was $27.53^{\circ}$, and the permeability coefficient was $1.14 e-04 \mathrm{~cm} / \mathrm{s}$. Compared with the original tailings material, the tailing floc cohesive force greatly increased, the internal friction angle slightly increased, and the permeability coefficient also improved.

\section{Conclusions}

(1) Through a single-factor sedimentation experiment, the effects of four flocculants on the flocculation and sedimentation of ultrafine tailings slurries were investigated, and the optimum type and blending of each flocculant when added alone were obtained. The optimum polyacrylamide was cationic with a molecular weight of 10 million and a dose of $3 \%$; the optimum content of polyaluminum chloride was 28 at a dose of $0.1 \%$; the optimum dose of polyaluminum sulfate was $1 \%$; and the optimum dose of polymeric ferric sulfate was $1 \%$.

(2) The optimal ratio of the four flocculants for the flocculation effect was investigated by a four-factor and three-level orthogonal experiment, and the polyacrylamide dose was $2 \%$, the polyaluminum chloride had a content of 28 and a dose of $0.05 \%$, the polyaluminum sulfate dose was $1 \%$, and the polyferric sulfate dose was $1 \%$. The primary and secondary factors affecting sedimentation were polyacrylamide $>$ polyaluminum sulfate $>$ polyaluminum chloride $>$ polyferric sulfate.

(3) A dry density test, direct shear test, and permeation test of the tailings floc after the addition of flocculant were performed, and it was found that the dry density of the tailings floc had almost no change, the cohesive force greatly increased, the internal friction angle slightly increased, and the penetration increased. The coefficient also improved.

\section{Data Availability}

The data used to support the findings of this study are included within the article.

\section{Conflicts of Interest}

The authors declare that they have no conflicts of interest regarding the publication of this paper.

\section{Acknowledgments}

This research was supported by the National Key Research and Development Plan of China (no. 2017YFC0804609).

\section{References}

[1] Ministry of Land and Resources of the People's Republic of China, "China mineral resources," Report, Geological Publishing House, Beijing, China, 2016.

[2] T. Miettinen, J. Ralston, and D. Fornasiero, "The limits of fine particle flotation," Minerals Engineering, vol. 23, no. 5, pp. 420-437, 2010.

[3] G. Zhang, L. Tong, and Z. Li, "Discussion on the treatment method and development and utilization of ultrafine tailings," Metal Mine, vol. 2, pp. 171-177, 2017.

[4] F. Jun-Xiang, Hydraulic Transport with Slurry and Particle Materials, Tsinghua University Press, Beijing, China, 1994.

[5] D.-Q. Gan, L. Han, L. Zhi-yi et al., "Study on the flocculation settlement characteristics of fine-grained tailings," Mining Research and Development, vol. 37, no. 9, pp. 31-35, 2017, in Chinese.

[6] Y. Hu, A. Song, R. Han et al., "Research on the overflow problems of full tailings filling technology with large capacity based on the TRIZ theory," Mining Research and Development, vol. 37, no. 10, pp. 15-17, 2017, in Chinese.

[7] J. Addai-Mensah, "Enhanced flocculation and dewatering of clay mineral dispersions," Powder Technology, vol. 179, no. 12, pp. 73-78, 2007.

[8] C. Eswaraiah, S. K. Biswal, and B. K. Mishra, "Settling characteristics of ultrafine iron ore slimes," International Journal of Minerals, Metallurgy, and Materials, vol. 19, no. 2, pp. 95-99, 2012.

[9] H. Jiao, S. Wang, Y. Yang, and X. Chen, "Water recovery improvement by shearing of gravity-thickened tailings for cemented paste backfill," Journal of Cleaner Production, 2019, In press.

[10] C. Selomulya, X. Jia, and R. A. Williams, "Direct prediction of structure and permeability of flocculated structures and sediments using 3D tomographic imaging," Chemical Engineering Research and Design, vol. 83, no. 7, pp. 844-852, 2005.

[11] H. Jiao, H.-J. Wang, A.-X. Wu et al., "Rule and mechanism of flocculation sedimentation of unclassified tailings," Journal of University of Science and Technology Beijing, vol. 32, no. 6, pp. 702-707, 2010.

[12] D. Tao, B. K. Parekh, Y. M. Zhao, and P. Zhang, "Pilot-scale demonstration of deep cone ${ }^{\mathrm{TM}}$ paste thickening process for phosphatic clay/sand disposal," Separation Science and Technology, vol. 45, no. 10, pp. 1418-1425, 2008.

[13] R. Bürgera, J. J. R. Damascenob, and K. H. Karlsenc, “A mathematical model for batch and continuous thickening of flocculated suspensions in vessels with varying cross section," International Journal of Mineral Processing, vol. 73, no. 2-4, pp. 183-204, 2004.

[14] X. Wang, J. Zhao, and D. Zhang, "Optimal prediction model of flocculating sedimentation velocity of unclassified tailings," The Chinese Journal of Nonferrous Metals, vol. 25, no. 3, pp. 793-798, 2015, in Chinese. 
[15] X. Wang, Y.-Y. Qu, W. Hu, W. Han, and M. Wu, "Experiment research on factors influencing tailing pulp flocculation settling," Metal Mine, vol. 383, no. 5, pp. 149-151, 2008.

[16] Y. Wang, A. Wu, H. Wang, S. Liu, and B. Zhou, "Influence mechanism of flocculant dosage on tailings thickening," Journal of University of Science and Technology Beijing, vol. 35, no. 11, pp. 1419-1423, 2013, in Chinese.

[17] H.-J. Wang, Q. R. Cheng, A. X. Wu et al., "Study on the thickening properties of unclassified tailings and its application to thickener design," Journal of University of Science and Technology Beijing, vol. 33, no. 6, pp. 676-681, 2011, in Chinese.

[18] X. Z. Shi, H. Y. Hu, X. H. Du et al., "Experimental study on flocculating sedimentation of tailings slurry in a vertical sand tank," Mining and Metallurgical Engineering, vol. 30, no. 3, pp. 1-3, 2010, in Chinese. 


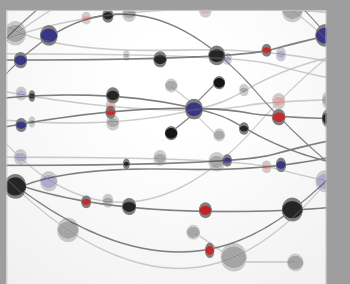

The Scientific World Journal
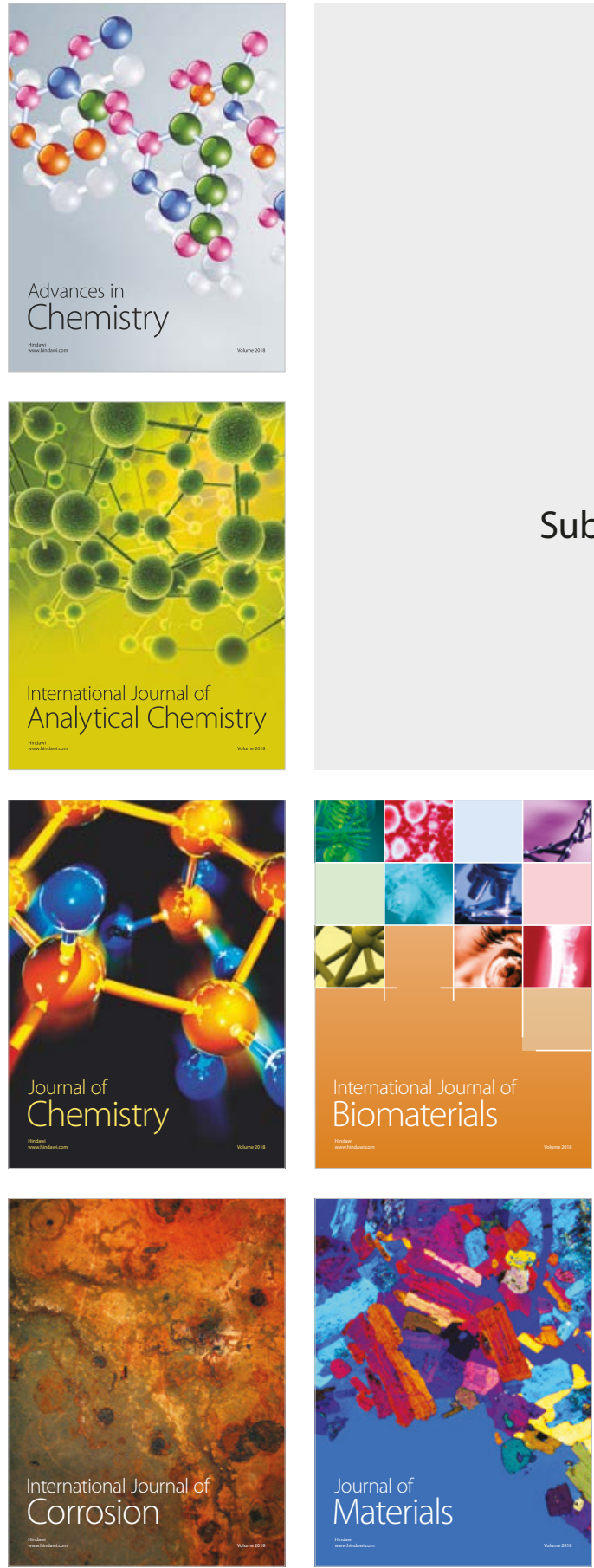

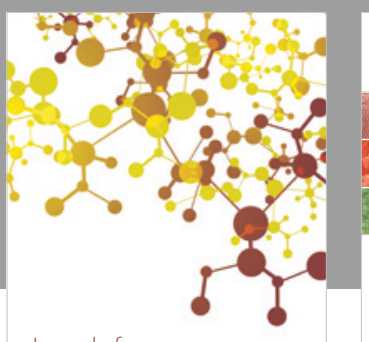

Journal of

Applied Chemistry
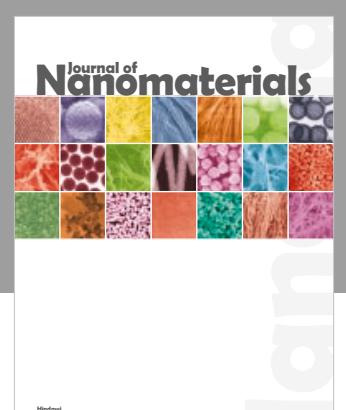

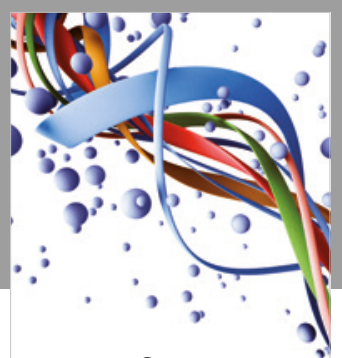

Scientifica

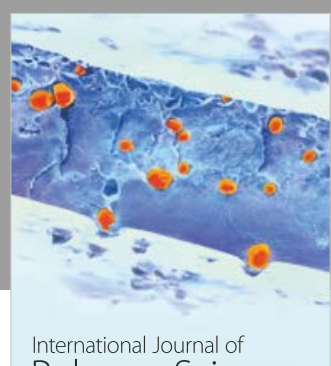

Polymer Science

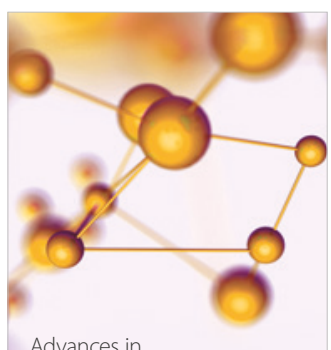

Physical Chemistry
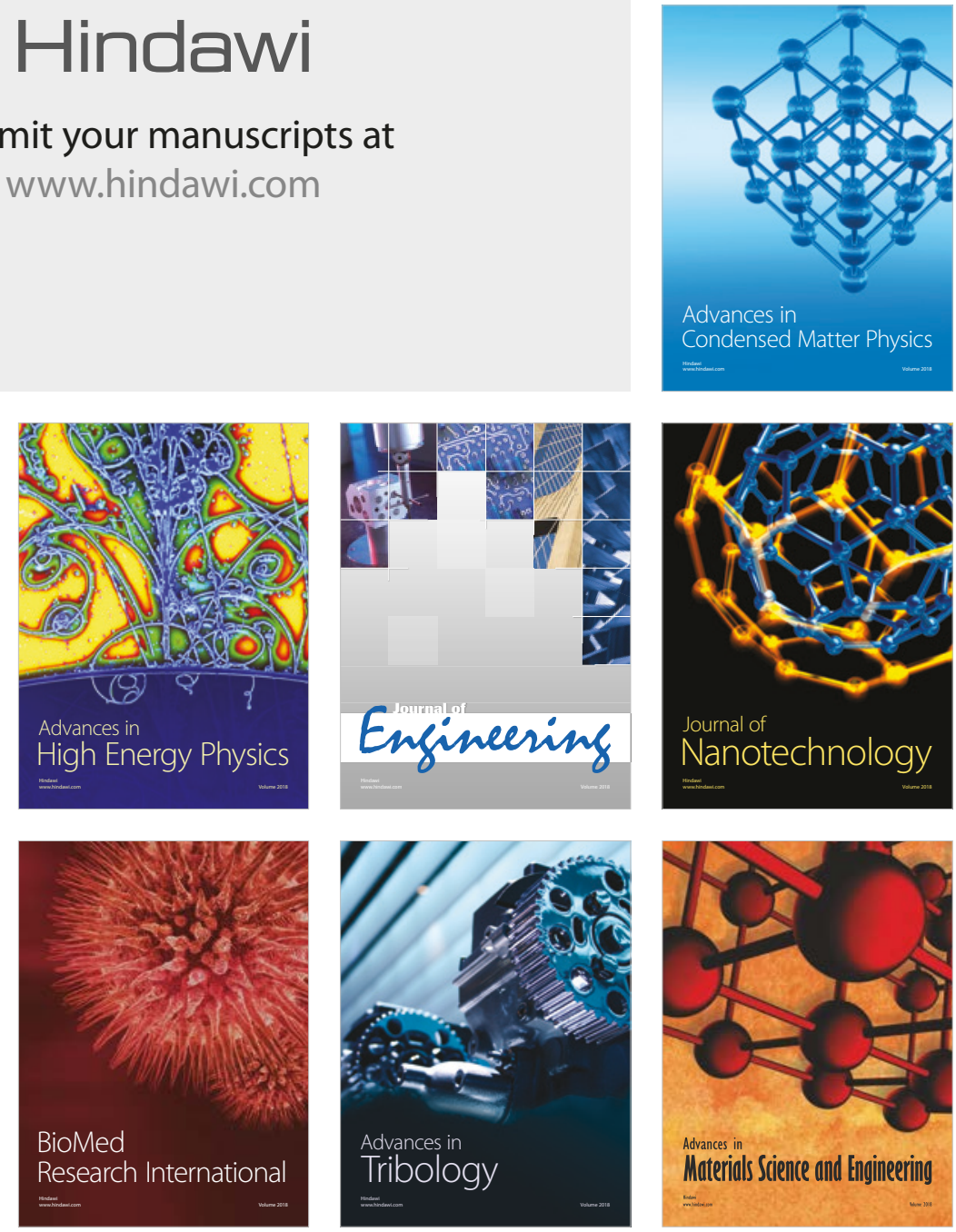